\title{
DETERMINANTS OF BLOOD DONATION STATUS IN MALAYSIA: PROFILING THE NON-DONORS, OCCASIONAL DONORS AND REGULAR DONORS
}

\section{Lim Mei Ling ${ }^{1}$, Thock Sheng Hui ${ }^{1}$, Andrew K. G. Tan ${ }^{1 *}$ and Gwee Sai Ling ${ }^{2}$}

${ }^{1}$ School of Social Sciences, Universiti Sains Malaysia, Pulau Pinang, MALAYSIA ${ }^{2}$ School of Business and Administration, Disted College, Pulau Pinang, MALAYSIA *Corresponding author: atan@usm.my

Published online: 27 April 2018

To cite this article: Lim, M. L., S. H. Thock, A. K. G. Tan and S. L. Gwee. 2018. Determinants of blood donation status in Malaysia: Profiling the non-donors, occasional donors and regular donors. Kajian Malaysia 36(1): 43-62. https://doi.org/10.21315/km2018.36.1.3

To link to this article: https://doi.org/10.21315/km2018.36.1.3

\begin{abstract}
The blood shortage situation is a perennial concern in Malaysia. This study examines the sociodemographic and lifestyle related factors associated with blood donation status of non-donors, occasional donors, and regular donors. Discerning the donation status of blood donors is important as studies have noted that it is more cost-effective to reactivate occasional (consisting of existing or former) donors than to recruit new donors. Based on stratified random sampling measures, primary data were obtained from 550 Malaysian adults aged 18-60 years from Pulau Pinang, Malaysia. Ordered probit analysis was conducted and marginal effects of various factors on blood donation status calculated. Results indicate that sociodemographic factors associated with donor status include gender, marital status, education level, and income level. Lifestyle related factors affecting donor status comprise working hours, family history, and fear of the donation process. It is concluded that donor awareness and education programs should be focused on females, singles, and individuals in the lower socioeconomic echelons. Donor retention strategies should be aimed at those with previous family history of blood recipients. Measures should be implemented to accommodate busy people and those fearful of the donation process. These strategies could be undertaken not only in Malaysia but also in other countries with comparable sociodemographic and health care settings.
\end{abstract}

Keywords: blood donation, Malaysia, non-donor, occasional donor, regular donor, ordered probit model 


\section{INTRODUCTION}

Blood procurement in Malaysia is centred on voluntary non-remunerated sources (Ministry of Health Malaysia, 2006). On this basis, total number of blood donations from mobile sites, blood collection centres, and hospitals increased by $86.7 \%$ from 361,898 to 675,315 cases between 2000-2014 (Figure 1). Total number of blood transfusions increased by $123.5 \%$ from 151,504 to 338,598 times during the same period. By type of donors, greater growth is seen among repeat donors $(37.1 \%)$ than new donors (13.3\%) between 2008-2014 (Ministry of Health Malaysia, 2006; 2007; 2009; 2011; 2014).

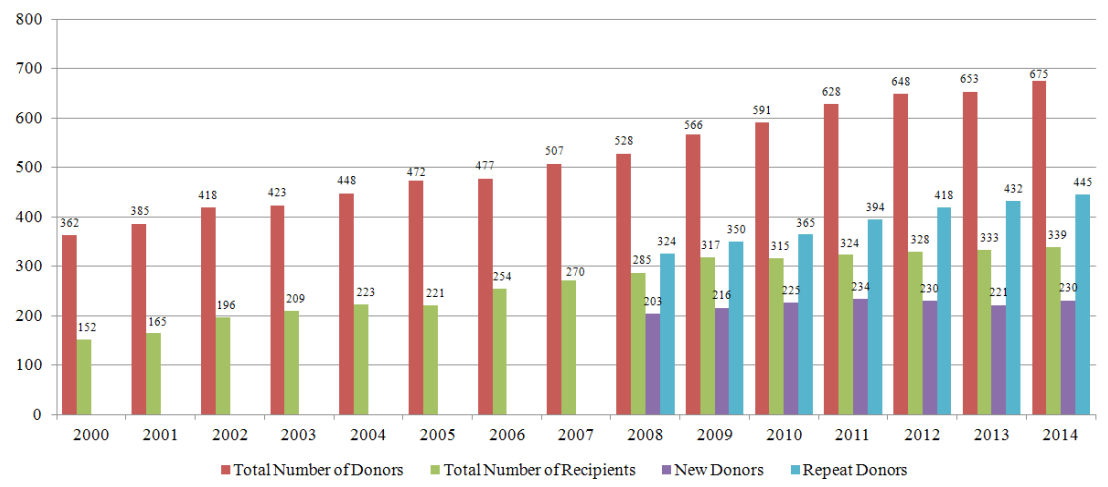

Figure 1: Total number of donors, recipients, new donors, and repeat donors in Malaysia (2000-2014).

Source: Ministry of Health Malaysia $(2006 ; 2007 ; 2009 ; 2011 ; 2014)$.

Despite the growth in total donor numbers, chronic blood shortages still persist amidst dwindling donor population and rising demand (Wooi Seong, Raffeal and Ayob, 2014). In fact, the blood donation rate in Malaysia is still low as only $2.2 \%$ of the entire population are donors compared to $3.5 \%-5.0 \%$ recorded in developed countries in 2014 (Bernama, 2015). While the World Health Organization (WHO) states that blood donation rates are 33.1, 11.7, and 4.6 donations per 1000 people for high-, middle-, and low-income countries, respectively (World Health Organization, 2016), the current Malaysian scenario translates to only 22.5 donations per 1000 people. This suggests that much needs to be done to improve donation rates ahead of the Malaysian government's target dateline of attaining industrialised nation status by 2020 (Jabatan Perdana Menteri, 2010).

The blood shortage situation in Malaysia is manifested by the fact that much of the growth in donor numbers are within repeat donors instead of new donors. Moreover, an average of 2,000 bags of blood are needed to treat almost 
1,000 patients throughout the nation daily (Bernama, 2015). This follows various reports that about $3 \%-5 \%$ or 1 in 20 (1.5 million) Malaysians are estimated to be carriers of the thalassaemia gene, an inherited disease of blood disorder requiring regular blood transfusions (The Star, 2010; Ngim et al., 2013). The national blood requirement is also exacerbated by the lack of donors during various festive and school holidays observed seasonally in Malaysia, although recent proactive measures undertaken by the Malaysian National Blood Centre has improved the situation (Lim, 2014; Wooi Seong, Raffeal and Ayob, 2014).

Given the blood shortage situation in Malaysia, it is desirable to identify the factors associated with donation status at the population level. This allows for a better understanding of donor and non-donor patterns and the factors associated with each subgroup. However, a review of the existing literature suggests that there exists a paucity of studies identifying the determinants of blood donation status in Malaysia.

This study offers two salient contributions. First, although there exist studies detailing blood supply challenges and shortages in Malaysia (Wooi Seong, Raffeal and Ayob, 2014; Wooi Seong, 2017), none has addressed the sociodemographic and lifestyle related factors associated with blood donation status at the population level. This study augments the literature by examining the association between such factors and blood donation status based on data from the state of Pulau Pinang, Malaysia. Second, studies have employed the conventional binary logistic or probabilistic models to examine the dichotomous decisions of donors and non-donors (Veldhuizen et al., 2009; Volken et al., 2013; Ou et al., 2015; Ou-Yang et al., 2017), thus compromising the information on occasional and regular donors. We extend the analysis to multi-level outcomes using an ordered probit model to study the donation statuses of non-, occasional-, and regulardonors. Identification of blood donor profiles, particularly those in the occasional and regular donor subgroups is relevant as the World Health Organization (2010) highlights the cost-effectiveness of reactivating occasional (consisting of existing or former) donors instead of recruiting new donors given their familiarity with the donation process. A better understanding of the determinants of blood donation status provides health policy-makers in Malaysia, and also other countries with comparable sociodemographic and health care settings, with baseline information to target segments of the population to meet the nation's need for safe blood.

\section{INSIGHTS FROM THE LITERATURE}

Studies have examined blood donation patterns and its association with sociodemographic and lifestyle-behavioural characteristics. For example, Cimaroli (2012) notes that families with more children at home exhibit lower likelihoods 
of multiple blood donations annually while singles are positively associated with donation frequency. This could be attributed to the busy schedules and priorities of families with more children whereas singles face less time constraints. According to Dilsad et al. (2014), individuals may forgo blood donation due to responsibilities in caring for family or if there is nobody to mind their children. This follows the findings of Carrier, Cloutier and Charbonneau (2015) that while family relationship is a primary motivator for parents to donate blood, the preferred timing is when their children are not around. From these outcomes, it is hypothesised that number of children will be inversely related with donation status in the current study.

Hollingsworth and Wildman (2004) and Burgdorf et al. (2017) find that time constraints due to a busy working schedule and a changing structure of society may constrain blood donation likelihoods. Meanwhile, Kasraian (2010) indicates that the most frequent reason for lapsed donation is a lack of time due to work. As noted by Guest, Munro, and Cookson (1998), the annual costs of blood transfusions can be significant as aside from direct costs (e.g. hospital resources, transport, etc.), donors incur indirect costs due to lost productivity (e.g. sick/annual leave, absence from work, etc.), while giving up leisure time in the donation process. These findings suggest that length of work hours may be negatively associated with blood donation status as those who are busier will have less time to donate. Moreover, within the subgroups of occasional and regular donors, a higher likelihood would be expected within the former than the latter as busy people are more likely to lapse in their donation regularity.

Ethnic backgrounds are often significant predictors of blood donation patterns. Boulware et al. (2002) and Burgdorf et al. (2017) assert that in the United States (U.S.), African-Americans often exhibit lower propensities to donate blood compared to Caucasians. James et al. (2011) attribute this racial difference in the willingness to donate to distrust of the health care system in the US among AfricanAmericans. In a multi-ethnic donor population like Malaysia, consisting of Malays (54.7\%), Chinese (24.7\%), Indians (7.4\%), and various others races (13.2\%) (Department of Statistics Malaysia, 2008), it is conceivable that ethnic background may play an important role in blood donation practices. In fact, Wooi Seong (2017) observes that in the past, ethnic Chinese may be apprehensive of donating blood due to traditional beliefs that it could result in negative health effects or bad karma when visiting hospital blood banks during auspicious periods. Similarly, blood banks in Malaysian hospitals often run low during the fasting month of Ramadan given the lack of Malay donors who are discouraged from donating for health reasons. As such, while ethnic groups are included in the current study to examine its possible link with blood donation status, no a priori expectations are held.

Various studies have pointed to the role of gender as an important catalyst to being a blood donor. In these studies, males often exhibit higher likelihoods of donating and being frequent donors than females (Volken et al., 2013; Ou et al., 
2015). Nevertheless, while it is important to recognise that donor frequency should be gender adjusted as the maximum number of donations permitted annually may be different for adult males (four) and females (three), other reasons may account for lower donation rates among women too. According to Veldhuizen et al. (2009) and Shenga et al. (2010), females often stop donating much earlier in their donor careers than their male counterparts. This is because women are disallowed from donating during pregnancy or breastfeeding periods, and thus quit donating permanently instead of resuming to donate later. Another possible reason accounting for lower donation rates among women include health concerns, such as iron-deficiency anaemia or low body weight (Boulware et al., 2002; Kasraian, 2010). It is therefore posited that males would exhibit higher likelihoods of being occasional or regular donors than females in the current study.

Studies on the role of age on blood donor patterns have generally shown mixed outcomes. For instance, Marantidou et al. (2007) note that young people are less likely to donate in Greece, while Kasraian (2010), Volken et al. (2013), and Ou et al. (2015) report higher response rates among older donors in Iran, Germany, and Hong Kong, respectively. Meanwhile, Boulware et al. (2002), Wiwanitkit (2002), and Shenga et al. (2010) find no discerning association between age and knowledge or actual blood donation in U.S., Thailand, and India, respectively. Nonetheless, it is interesting to note the findings of Wooi Seong (2017) that the majority of blood donors in Malaysia are predominantly from the younger age group of 17-35 years. Given the overall mixed outcomes, the association between age and blood donor patterns will be further ascertained, albeit with close attention on the contribution of the younger donors.

The role of marital status on blood donation decisions is inconclusive. For example, Gillespie and Hillyer (2002) and Veldhuizen et al. (2009) conclude that blood donation is most common among married people. Mesch et al. (2011) attribute this outcome to the better social network connectivity enjoyed by married persons that motivate their donation behaviour to do good to others. Interestingly, Burgdorf et al. (2017) stress that while blood donation status is strongly linked with cohabitation status among Danish men, the effects are less clear for women. In other words, being married serves as a strong positive predictor of blood donation only among men, while the association is not as evident for women. Meanwhile, Kasraian (2010) and Shenga et al. (2010) find no significant relationship between blood donation knowledge and marital status. Thus, the role of marital status on blood donation status will be further examined in the current study.

Studies generally affirm the impact of socioeconomic status (as measured by education level or individual income) in affecting blood donation practices, although the exact relationships are unclear a priori. For instance, Cimaroli (2012) finds that highly educated populations are less likely to donate blood frequently. Similarly, Saberton et al. (2009) point to the inverse relationship between average 
household income and donor numbers in large cities. In contrast, Veldhuizen et al. (2009) and Carrier, Cloutier and Charbonneau (2015) note that one of the primary characteristics of blood donors is the better than average education. Meanwhile, findings by Burgdorf et al. (2017) suggest individuals within higher income brackets form the majority of the blood donor population, while Veldhuizen et al. (2009) and Carrier, Cloutier and Charbonneau (2015) conclude that nonremunerated blood donation is typically associated with those in the affluent social class. Possible rationalisations for these outcomes vary. It is possible that time constraints of a demanding lifestyle among better educated individuals may hinder donation frequencies. Likewise, persons with higher income levels may also face higher time costs, thus dampening their donation likelihoods. However, better educated individuals may also be more conscious of the vital role of blood donation while individual affluence may contribute to greater access to health information. Based on these outcomes, no hypothesised relationships are posited for the socioeconomic variables of education and income in the present study.

As suggested by Piliavin and Callero (1991), and Glynn et al. (2006), the role of life experience (e.g. knowing a family member/friend who needs blood transfusion) is positively associated with blood donation decisions. Healy (2000) attributes this outcome to "network effects", whereby being associated with family/ friends with blood needs result in higher donation probabilities by one's own self. Two possible explanations are offered. First, individuals with family members/ friends requiring emergency blood/organ transfusion may have better knowledge and familiarity with the donation process. Second, individuals with life experience for the need of a valuable resource such as blood are better able to empathise with the situation and would thus be more likely to donate to others in return. Therefore, a positive association is expected between blood donation status and those with family members/friends who received blood/organ transfusion in the past.

Studies have shown that hemophobia (fear of blood), trypanophobia (fear of needles), and even the general fear of the entire donation process are valid concerns that may discourage blood donations. Marantidou et al. (2007) assert that among the predominant reasons for not returning to donate is due to the fear of needles/pain/fainting during the collection process. Meanwhile, Hupfer, Taylor, and Letwin (2005) allude to the negative factors of the sight of blood and apprehension of the overall blood procurement process as reasons for avoiding donation. As such, it is hypothesised that a general fear of the donation process would have a negative effect on blood donation status. 


\section{MATERIALS AND METHODS}

\section{Data}

Primary data for this exploratory study were obtained by questionnaire-based faceto-face interviews among residents in Pulau Pinang, Malaysia from 1 January to 20 March, 2016. A pilot study with ten respondents, comprising five academic/ administrative staff and five undergraduate students of Universiti Sains Malaysia, was initially conducted to pre-test the reliability of the questionnaires and to establish the presence of any prospective issues. From the pilot study, several parts of the questionnaire were edited for clarity. For instance, respondents were initially asked to report their monthly household income in the pilot questionnaire. However, due to confidentiality concerns observed during the pilot study, it was felt that respondents would be more at ease to select their income bracket rather than to disclose their actual income. Additionally, the unit of measurement was altered to individual monthly income as it was felt that blood donation decisions are individualistic in nature instead of a household decision.

The sample was stratified according to ethnicity, gender, and age to reflect the population of the state of Pulau Pinang, Malaysia (Penang Institute, 2014). Interviews were conducted at various public places in Pulau Pinang (e.g. bus stations, ferry jetty, markets, and events and fairs). Respondents were randomly approached and the purpose of the study explained in either Bahasa Malaysia or English. Upon obtaining verbal consent to participate in the study, respondents were asked if they were between 18-60 years old (World Health Organization, 2012) and whether they had resided in Pulau Pinang for the past 12 months from the date of the survey. Having confirmed the age and residential requirements, respondents were asked questions regarding their sociodemographic and lifestyle particulars, and blood donation patterns. A total sample of 550 respondents was collected, with a gender breakdown of $276(50.2 \%)$ males and 274 (49.8\%) females.

\section{Definition of Variables}

The dependent variable in this study describes blood donor status according to the number of times donated as self-reported by the respondents. This follows guidelines by the WHO (World Health Organization, 2012) in accessing donor sustainability for blood donation as the minimum interval between donations of whole blood for males should be 12 weeks ( 3 months) and 16 weeks ( 4 months) for women. This suggests that males (females) can donate a maximum of 4 (3) times annually. Therefore, a person with 3-4 (2-3) times of yearly donation is considered as regular donor for a male (female); 1-2 (1) time(s) in the past year is classified as occasional donor for a male (female); and, 0 time in a lifetime is 
considered as a non-donor for both genders. Past donors who do not fulfill the regular donor requirements as stated above (i.e. lapsed donors) are classified as occasional donors due to their non-regular frequency.

Sociodemographic variables hypothesised to affect blood donor status relies on insights from previous studies (Glynn et al., 2006; Veldhuizen et al., 2009; Kasraian, 2010; Burgdorf et al., 2017): (1) ethnicity, (2) gender, (3) age group, (4) marital status, (5) education level, (6) income bracket, and (7) number of child(ren) in household. Lifestyle variables hypothesised to be associated with donor status include: (8) working hours, (9) family history of receiving blood/ organ transfusion, and (10) fear of the blood donation process, including the sight of blood/needles (Table 1).

Table 1: Definitions and sample means of explanatory variables

\begin{tabular}{|c|c|c|c|c|c|c|}
\hline Variable & Definition & $\begin{array}{l}\text { Non- } \\
\text { donor }\end{array}$ & $\begin{array}{l}\text { Occasional } \\
\text { donor }\end{array}$ & $\begin{array}{c}\text { Regular } \\
\text { donor }\end{array}$ & Total & $\begin{array}{c}\text { Pulau } \\
\text { Pinang } \\
\text { population }^{* * *}\end{array}$ \\
\hline \multicolumn{7}{|c|}{ Continuous variables } \\
\hline $\begin{array}{l}\text { Number } \\
\text { child }\end{array}$ & $\begin{array}{l}\text { Number of } \\
\text { child(ren) in } \\
\text { household }\end{array}$ & $\begin{array}{c}0.84 \\
(1.22)\end{array}$ & $\begin{array}{c}1.08 \\
(1.26)\end{array}$ & $\begin{array}{c}1.15 \\
(1.27)\end{array}$ & $\begin{array}{c}0.94 \\
(1.24)\end{array}$ & - \\
\hline $\begin{array}{l}\text { Working } \\
\text { hours }\end{array}$ & $\begin{array}{l}\text { Number of } \\
\text { hours worked } \\
\text { weekly }\end{array}$ & $\begin{array}{c}32.78 \\
(22.58)\end{array}$ & $\begin{array}{c}38.09 \\
(18.91)\end{array}$ & $\begin{array}{l}33.84 \\
(20.82)\end{array}$ & $\begin{array}{c}34.24 \\
(21.58)\end{array}$ & - \\
\hline \multicolumn{7}{|c|}{ Binary variables $(\mathrm{Yes}=1 ; \mathrm{No}=0)$} \\
\hline Malay & $\begin{array}{l}\text { Ethnicity is } \\
\text { Malay }\end{array}$ & 0.44 & 0.43 & 0.44 & 0.43 & 0.44 \\
\hline Chinese & $\begin{array}{l}\text { Ethnicity is } \\
\text { Chinese }\end{array}$ & 0.46 & 0.46 & 0.46 & 0.46 & 0.45 \\
\hline Indian & $\begin{array}{l}\text { Ethnicity is } \\
\text { Indian/others } \\
\text { (reference) }\end{array}$ & 0.11 & 0.11 & 0.10 & 0.11 & 0.11 \\
\hline Male & Gender is male & 0.41 & 0.70 & 0.57 & 0.50 & 0.50 \\
\hline Age $18-29$ & $\begin{array}{l}\text { Age is between } \\
18-29 \text { years }\end{array}$ & 0.31 & 0.25 & 0.24 & 0.29 & 0.29 \\
\hline Age 30-39 & $\begin{array}{l}\text { Age is between } \\
30-39 \text { years }\end{array}$ & 0.25 & 0.30 & 0.43 & 0.29 & 0.27 \\
\hline Age $40-49$ & $\begin{array}{l}\text { Age is between } \\
40-49 \text { years }\end{array}$ & 0.23 & 0.26 & 0.21 & 0.23 & 0.24 \\
\hline Age $50-60$ & $\begin{array}{l}\text { Age is between } \\
50-60 \text { years } \\
\text { (reference) }\end{array}$ & 0.21 & 0.19 & 0.13 & 0.20 & 0.19 \\
\hline
\end{tabular}


Table 1: (continued)

\begin{tabular}{|c|c|c|c|c|c|c|}
\hline Variable & Definition & $\begin{array}{l}\text { Non- } \\
\text { donor }\end{array}$ & $\begin{array}{l}\text { Occasional } \\
\text { donor }\end{array}$ & $\begin{array}{c}\text { Regular } \\
\text { donor }\end{array}$ & Total & $\begin{array}{c}\text { Pulau } \\
\text { Pinang } \\
\text { population }^{* * *}\end{array}$ \\
\hline Singles & $\begin{array}{l}\text { Single/ } \\
\text { Divorced/ } \\
\text { Widowed }\end{array}$ & 0.44 & 0.30 & 0.35 & 0.39 & - \\
\hline Tertiary & $\begin{array}{l}\text { Highest level } \\
\text { of education is } \\
\text { tertiary level }\end{array}$ & 0.36 & 0.45 & 0.63 & 0.42 & - \\
\hline $\begin{array}{l}\text { Low- } \\
\text { income }\end{array}$ & $\begin{array}{l}\text { Individual } \\
\text { monthly income } \\
\leq \mathrm{RM} 1500^{*}\end{array}$ & 0.39 & 0.20 & 0.26 & 0.33 & - \\
\hline $\begin{array}{l}\text { Mid- } \\
\text { income }\end{array}$ & $\begin{array}{l}\text { Individual } \\
\text { monthly income } \\
\text { RM1501- } \\
\text { RM6000 }\end{array}$ & 0.53 & 0.70 & 0.60 & 0.58 & - \\
\hline $\begin{array}{l}\text { High- } \\
\text { income }\end{array}$ & $\begin{array}{l}\text { Individual } \\
\text { monthly income } \\
\geq \text { RM6001 } \\
\text { (reference) }\end{array}$ & 0.07 & 0.10 & 0.13 & 0.09 & - \\
\hline $\begin{array}{l}\text { Family } \\
\text { recipient }\end{array}$ & $\begin{array}{l}\text { Has family } \\
\text { members receive } \\
\text { blood/organ } \\
\text { transfusion in } \\
\text { past }\end{array}$ & 0.12 & 0.20 & 0.10 & 0.14 & - \\
\hline Fear & $\begin{array}{l}\text { Admits to being } \\
\text { fearful of the } \\
\text { donation process } \\
\text { and sight of } \\
\text { blood/needles }\end{array}$ & 0.32 & 0.18 & 0.10 & 0.26 & - \\
\hline $\begin{array}{l}\text { Sample } \\
\text { size }\end{array}$ & & 344 & 138 & 68 & 550 & 873,700 \\
\hline $\begin{array}{l}\text { Percent } \\
(\%)\end{array}$ & & 62.54 & 25.10 & 12.36 & 100.00 & - \\
\hline
\end{tabular}

Note: Values in percentages. Standard deviation in parentheses.

Source: Compiled by researchers.

"As of 5 January 2017, the exchange rate was approximately USD1.00 = RM3.95 or RM1.00 = USD0.25.

** Source: Penang Institute (2014). Available data for age groups refer to 20-29 years, 30-39 years, 40-49 years, and 50-59 years.

Specifically, respondent's ethnicity is categorised according to the three primary ethnic groups in Malaysia (Malay, Chinese, Indian). ${ }^{1}$ Other sociodemographic characteristics include gender (Male) and age groups (1829 years, 30-39 years, 40-49 years, 50-60 years), marital status (Singles), and 
education level (Tertiary). Individual monthly income is grouped according to low (individual monthly income $\leq \mathrm{RM} 1,500, \leq \mathrm{USD} 380$ ), ${ }^{2}$ middle (RM1,501RM6,000, USD381-USD1,519), and high ( $\geq$ RM6,001, $\geq$ USD1,520) income groups. Continuous sociodemographic variables include the number of children in the household (Number child) and number of hours worked weekly (Working hours). Lifestyle related variables hypothesised to influence blood donor status are whether the respondent has family members receiving blood/organ transfusion in the past (Family recipient) and whether the respondent admits to fear of the donation process (Fear).

\section{Statistical Analysis}

Given that our dependent variable (y) is categorical and defined in an ordinal scale, we use an ordered probit model (McKelvey and Zavoina, 1975; McCullagh, 1980) for the analysis. The ordered probability model (McCullagh, 1980) is characterised as:

$$
\begin{aligned}
\text { Blood donor status } & =\text { Non - donor } & \text { if } & -\infty<x \beta+u \leq 0 \\
& =\text { Occasional donor } & \text { if } & 0<x \beta+u \leq \mu_{1} \\
& =\text { Regular donor } & \text { if } & 0<x \beta+u \leq \mu_{2}
\end{aligned}
$$

where, $\chi$ is a vector of explanatory variables with parameters $\beta, u$ is a random disturbance term, and the $\mu$ 's are threshold parameters which delineate the donor categories. The probability of each category can be derived from (1). For example, the probability of being a regular donor is:

$\operatorname{Pr}($ Regular $)=F(\mu 2-\chi \beta)-F(\mu 1-\chi \beta)$,

where, $F($.$) is the cumulative distribution function of the standard normal$ distribution. The probabilities of other donor categories are similar, with the use of proper threshold parameters. The ordered probit model, estimated by the method of maximum-likelihood (ML) (Maddala, 1986), is based on probability expressions similar to (2). Based on ML estimates, the effects of explanatory are derived by differentiating (or differencing, in the case of a discrete variable) the category probabilities, in (2) (Powers and Xie, 2008).

To check for multicollinearity among explanatory variables, we calculate the variance inflation factor (VIF) for each variable. While VIF values over 20 are illustrative of multicollinearity problems (Belsley, Kuh, and Welsch, 2004), all variables in the current study yield VIFs of less than 5, with the highest values for Low- (4.94) and Mid- (3.50) income groups. Hence, there exists no evidence of multicollinearity among the explanatory variables. 


\section{RESULTS}

\section{Characteristics of Respondents}

Descriptive statistics of all explanatory variables and blood donation categories are presented in Table 1 while Figure 2 provides a breakdown of number of respondents by sociodemographic characteristics and donor status. With a total of 550 respondents, the number of non-donors $(344,62.5 \%)$ far outweigh occasional $(138,25.1 \%)$ and regular $(68,12.4 \%)$ donors.

The ethnic breakdown of the total sample (43.0\% Malays, $46.0 \%$ Chinese and $11.0 \%$ Indians/others) reflects the ethnic composition of Pulau Pinang in 2014: 44.3\% Malays, $44.7 \%$ Chinese, and $11.0 \%$ Indians/others. Gender composition of both the entire sample and Pulau Pinang population are equally distributed. By age group, the proportions of both the total sample and Pulau Pinang population are broadly similar (Penang Institute, 2014).

The majority $(61.0 \%)$ of the whole sample are married. Although less than half of the entire sample $(42 \%)$ possesses tertiary education, the proportion of those educated up to the tertiary level is higher among regular donors $(63.0 \%)$ than non-donors $(36.0 \%)$. The majority of the total sample $(58.0 \%)$ consists of middle-income earners with individual monthly income RM1,501-RM6,000. About $14 \%$ of the whole sample report having family members receive blood/ organ transfusion. Approximately $26 \%$ of the entire sample admit to being fearful of the donation process, with $32.0 \%$ of non-donors reporting apprehension of the procedure (Table 1).

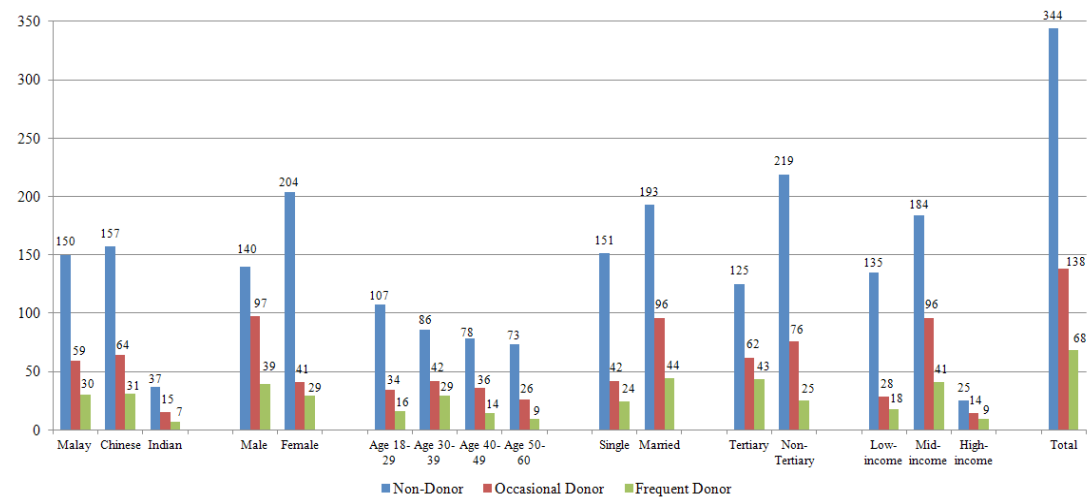

Figure 2: Breakdown of number of respondents by sociodemographic characteristics and donor status. 


\section{Marginal Effects of Explanatory Variables}

Table 2 presents marginal effects of explanatory variables on the probabilities of blood donor status. Working hours is a factor, as each additional hour spent at work lowers the likelihood of being an occasional and regular donor by 0.16 and 0.14 percentage points (henceforth, point(s)), respectively, whilst increasing the likelihood of being a non-donor by 0.29 points, all else equal.

Table 2: Marginal effects of explanatory variables on blood donor status probabilities

\begin{tabular}{|c|c|c|c|}
\hline \multirow{2}{*}{ Variable } & \multicolumn{3}{|c|}{ Probabilities ( $\times 100$ of blood donor categories) } \\
\hline & Non-donor & Occasional donor & Regular donor \\
\hline \multirow[t]{2}{*}{ Number child } & -0.69 & 0.37 & 0.32 \\
\hline & $(2.10)$ & $(1.13)$ & $(0.98)$ \\
\hline \multirow[t]{2}{*}{ Working hours } & $0.29^{*}$ & $-0.16^{*}$ & $-0.14^{*}$ \\
\hline & $(0.15)$ & $(0.08)$ & $(0.07)$ \\
\hline \multirow[t]{2}{*}{ Malay } & 0.23 & -0.12 & -0.11 \\
\hline & $(6.80)$ & $(3.65)$ & $(3.15)$ \\
\hline \multirow[t]{2}{*}{ Chinese } & 3.78 & -2.03 & -1.75 \\
\hline & $(6.79)$ & $(3.66)$ & $(3.13)$ \\
\hline \multirow[t]{2}{*}{ Male } & $-16.88^{* * *}$ & $8.95^{* * *}$ & $7.93^{* * *}$ \\
\hline & $(4.13)$ & $(2.30)$ & $(2.05)$ \\
\hline \multirow[t]{2}{*}{ Age $18-29$} & -6.10 & 3.17 & 2.93 \\
\hline & $(6.45)$ & $(3.26)$ & $(3.21)$ \\
\hline \multirow[t]{2}{*}{ Age 30-39 } & 3.47 & -1.90 & -1.57 \\
\hline & $(6.91)$ & $(3.85)$ & $(3.06)$ \\
\hline \multirow[t]{2}{*}{ Age $40-49$} & 4.97 & -2.75 & -2.22 \\
\hline & (7.02) & $(4.00)$ & (3.03) \\
\hline \multirow[t]{2}{*}{ Singles } & $10.28^{*}$ & $-5.62^{*}$ & $-4.66^{*}$ \\
\hline & $(5.83)$ & $(3.27)$ & $(2.62)$ \\
\hline \multirow[t]{2}{*}{ Tertiary } & $-14.18^{* * *}$ & $7.35^{* * *}$ & $6.83^{* * *}$ \\
\hline & $(4.28)$ & $(2.24)$ & (2.19) \\
\hline \multirow[t]{2}{*}{ Low-income } & $18.32^{* *}$ & $-10.34^{* *}$ & $-7.98^{* *}$ \\
\hline & $(8.74)$ & $(5.20)$ & $(3.67)$ \\
\hline \multirow[t]{2}{*}{ Mid-income } & 2.72 & -1.45 & -1.27 \\
\hline & (7.17) & $(3.81)$ & $(3.37)$ \\
\hline
\end{tabular}


Table 2: (continued)

\begin{tabular}{cccc}
\hline \multirow{2}{*}{ Variable } & \multicolumn{2}{c}{ Probabilities $(\times \mathbf{1 0 0}$ of blood donor categories) } \\
\cline { 2 - 4 } & Non-donor & Occasional donor & Regular donor \\
\hline Family recipient & $-12.45^{* *}$ & $5.99^{* *}$ & $6.46^{*}$ \\
& $(5.76)$ & $(2.51)$ & $(3.35)$ \\
Fear & $18.67^{* * *}$ & $-10.83^{* * *}$ & $-7.84^{* * *}$ \\
& $(4.28)$ & $(2.80)$ & $(1.74)$ \\
\hline
\end{tabular}

Note: Standard errors in parenthesis.

Asterisks indicate levels of statistical significance: ${ }^{* * *} p \leq 0.01,{ }^{* *} p \leq 0.05,{ }^{*} p \leq 0.10$

Reference categories are Indian/others for ethnicity, Age 50-60 for age group, and High-income for individual monthly income.

Gender is significantly associated with blood donor status. Males face higher propensities of being occasional ( 8.95 points) than regular ( 7.93 points) donors. Overall, males are 16.88 points less likely to be non-donors than females. Marital status is weakly correlated with blood donation status. Singles are 10.28 points more likely to be non-donors and are less likely to be occasional (5.62 points) and regular (4.66 points) blood donors, everything else constant.

Socioeconomic status is correlated with blood donation status. Education level is significantly associated with blood donor status as tertiary educated individuals are more likely to be occasional (7.35 points) and regular (6.83 points) blood donors than their non-tertiary educated cohorts. Overall, persons educated up to the tertiary level are 14.18 points less likely to be non-donors compared to those who are non-tertiary educated. Additionally, individuals from the low income group are 10.34 and 7.98 points less likely to be occasional and regular blood donors, respectively, than their high income peers. On the whole, low income earners are 18.32 points more likely to be non-donors relative to their high income counterparts.

Individuals with family members/friends previously receiving blood/ organ transfusion are more likely to be blood donors than those without such backgrounds. In fact, those with such experience exhibit even higher propensity to be regular (6.46 points) than occasional (5.99) donors. Overall, persons with family members/friends receiving previous blood/organ transfusion are 12.45 points less likely to be non-donors than those without such traits.

Being fearful of the donation process affects blood donation patterns negatively. Individuals acknowledging such fears are 10.83 points and 7.84 points less likely to be occasional and regular blood donors, respectively. Instead, apprehension of the donation process contributes to 18.67 higher points of being non-donors relative to those without such mindset. 


\section{DISCUSSION AND CONCLUDING REMARKS}

This study advances the understanding of sociodemographic and lifestyle related factors associated with blood donation status in Malaysia. The ordered probit model allows for a novel investigation of multi-level outcomes of non-, occasional-, and regular-donor statuses. Results indicate that sociodemographic factors associated with donor status include gender (males), marital status (singles), education level (tertiary), and income level (low). Lifestyle related factors affecting blood donor status comprise working hours, family history, and fear of the donation process. Based on these outcomes, several observations are highlighted.

First, current results corroborate previous findings (Volken et al., 2013; Ou et al., 2015) that males are more likely to be blood donors than females. Moreover, our findings distinguish the higher likelihood of males to be occasional donors (8.95 points) than regular donors (7.93 points). This is despite the fact that gender is adjusted for minimum intervals between donations in the current study since the maximum number of donations permitted annually in Malaysia is different for adult males (four) and females (three). One possible reason as posited by Veldhuizen et al. (2009) and Shenga et al. (2010) is because women are not allowed to donate during pregnancy or breastfeeding periods, and may quit donating permanently instead of resuming their donor practice. Another possible explanation for the lower donation rates among women include health concerns, such as irondeficiency anaemia or low body weight (Boulware et al., 2002; Kasraian, 2010). To overcome these barriers and improve donor turnout, education programs should be focused on females in Malaysia to raise blood donation awareness. Such programs should encourage female donors to resume donating after childbirth when their haemoglobin levels normalise. Health authorities should also consider providing iron supplements to female donors in order to allay their health concerns during the donation process.

Second, marital status is a significant determinant of blood donor status as singles are more likely to be non-donors than their married counterparts. In explaining this outcome, Mesch et al. (2011) credit better social networks or community connectedness among married people that motivate their donation behaviour to benefit others. To enhance donor recruitment, it would be prudent for the Malaysian health authorities to design donation campaigns focusing on family relationships in targeting married persons. Meanwhile, media promotions to encourage blood donation among singles could exalt the health benefits of donating to one's own well-being (e.g. reduced risks of cardiovascular diseases, hypertension, cancer) (Edgren et al., 2007; Kamhieh-Milz et al., 2016).

Third, our results corroborate previous findings (Veldhuizen et al., 2009; Burgdorf et al., 2017; Ou-Yang et al., 2017) that there exists a direct relationship between socioeconomic (whether measured by education or income) and blood 
donor statuses as tertiary educated and higher income individuals are more likely to be occasional or regular donors than those with lower education and income levels, respectively. Possible reasons for this result are that individuals in the upper socioeconomic class groups are more likely to be conscious of the importance of blood donation or may have greater access to health information. Meanwhile, lower educated and poorer individuals may be less exposed to the overall benefits of blood donation. Thus, efforts to increase donation likelihoods among those in the lower socioeconomic status groups may include more methodical and diverse communication channels (e.g. posters and leaflets, TV and radio public service broadcasts, newspapers, magazines) that are most likely to capture their attention (Misje et al., 2005; World Health Organization, 2010). Basic information as to why blood is required, how is it used, current blood supply stock, testimonials from donors and recipients, and the appointment of famous sports personalities, celebrities, and community and religious leaders as blood donation ambassadors are possible measures to be considered in reaching out to those in the lower socioeconomic echelons (World Health Organization, 2010). Announcements of the provision of free health check-ups, medical counseling, and light refreshments may also attract those in the underprivileged groups.

Fourth, current findings support prior studies (Glynn et al., 2006) that life experience affects blood donation patterns as those with a history of family members/friends receiving blood/organ transfusion exhibit positive likelihoods to be occasional and regular donors than those without such exposure. In fact, our study shows that the propensity of being a regular donor (6.46 points) is even higher than an occasional donor (5.99 points) in people with comparable backgrounds. Therefore, an important avenue in the search for new blood donors may lie in family members/friends of current donors (Holdershaw, Gendall and Wright, 2003). Additionally, extending non-monetary benefits to family members/ friends of donors (e.g. favourable policies of free blood transfusions or priorities to the blood bank in times of need) may also raise donation likelihoods of perspective blood donors (Ou-Yang et al., 2017).

Fifth, as our results indicate that blood donation likelihoods are inversely related to daily work hours, efforts should be made to reach out to busy Malaysians to become blood donors. This includes varying the operating hours of donation venues (e.g. operating during weekends or evenings) and reducing donation or waiting times so that donors do not view it as time consuming (Kasraian, 2010; Ou-Yang et al., 2017). Blood collection centers should consider sending reminders to donors who may be too busy to recall their next due date or establishing an appointment system to cater to those preferring to plan their schedule ahead (World Health Organization, 2010). Mobile donor sessions can also be organised at large corporations/factories, government departments, or universities, with popular buzz phrases such as Corporate Social Responsibility (CSR), whereby donors are 
allowed time off to donate. In doing so, donors would feel that they are getting something in return instead of thinking that they are constrained for time.

Last, individuals who report personal fears of the donation process display higher propensities to be non-donors and are less likely to be occasional or regular blood donors than those without such apprehensions. Consequently, it may be fruitful for the health authorities to engage in education programs to allay public apprehension and assure donors that the entire donation process is inherently safe and does not affect their health. Short video clips could be placed at strategic public places to show the entire donation process, with emphasis on the safety precautions undertaken, such as opening disposable sterile kits in front of donors at all times. Additionally, trained health staff participating in the donation process (particularly those performing the venepuncture) should provide professional service and quality care in responding to the concerns and anxieties of donors. These measures may quell negative automatic thoughts leading to phobic behavioural reactions towards blood donation (Stewart et al., 2006; World Health Organization, 2010).

Generally, our results suggest the need for future awareness and education programs to improve positive responses among females, singles, and individuals in the lower socioeconomic echelons. Donor retention strategies should be aimed at those with a family history of recipients. To increase blood supplies, strategies should be implemented to accommodate busy people and those fearful of the donation process. These strategies could be taken into account not only in Malaysia but also elsewhere as donor characteristics are likely to apply to other countries with comparable demographic and health care settings.

While this study serves as a catalyst to further investigations on the role of sociodemographic and lifestyle factors in affecting blood donor patterns in Malaysia, two important caveats are relevant. First, additional information (e.g. motivation and knowledge to donate, family/replacement donor status, accessibility and availability of blood donation facilities) or longitudinal panel data may provide useful perspectives to evaluate the robustness of our results. For instance, intertemporal decision changes may have been ignored in the current study. Second, data collection was confined to public places in the state of Pulau Pinang only, whereby survey sites were predominantly in urban or sub-urban neighbourhoods. Thus, responses from rural areas may have been neglected. While a larger data set encompassing individuals from other states in Malaysia may provide a more comprehensive understanding of the determinants of blood donation patterns, this is relegated as a suggestion for future research given existing time, economic and resource constraints. 


\section{NOTES}

1. Individuals of "Other" ethnic backgrounds (e.g. Sikh, Eurasian, Kadazan, etc.) are recategorised under Indians to form the "Indians/others" category given the small samples of both groups (less than $10 \%$ for both).

2. As of 5 January 2018, the exchange rate was approximately USD1.00 $=$ RM3.95 or $\mathrm{RM} 1.00=\mathrm{USD} 0.25$.

\section{REFERENCES}

Belsley, D. A., E. Kuh and R. E. Welsch. 2004. Detecting and assessing collinearity. In Regression diagnostics: Identifying influential data and sources of collinearity. New York: Wiley.

Bernama. 2015. Subramaniam: Only $2.2 \%$ of Malaysian population donate blood. The Sun Daily, 14 June.

Boulware, L. E., L. E. Ratner, P. M. Ness, L. A. Cooper, S. Campbell-Lee, T. A. LaVeist and N. R. Powe. 2002. The contribution of sociodemographic, medical, and attitudinal factors to blood donation among the general public. Transfusion 42(6): 669-678. https://doi.org/10.1046/j.1537-2995.2002.00120.x

Burgdorf, K. S., J. Simonsen, A. Sundby, K. Rostgaard, O. B. Pedersen, E. Sørensen, K. R. Nielsen, et al. 2017. Socio-demographic characteristics of danish blood donors. PLOS ONE 12(2): 1-11. https://doi.org/10.1371/journal.pone.0169112

Carrier, É., M. S. Cloutier and J. Charbonneau. 2015. Cities, villages, and suburbs: What sets them apart when it comes to giving blood? Canadian Geographer 59(4): 447-460. https://doi.org/10.1111/cag.12219

Cimaroli, K. 2012. The frequency of blood donation in Canada: An exploration of individual and contextual determinants. Masters thesis, School of Geography and Earth Sciences, McMaster University.

Department of Statistics Malaysia. 2008. Social statistics bulletin Malaysia 2008. Putrajaya: Department of Statistics Malaysia.

Dilsad, S., O. Tanriover, S. Hidiroglu, Y. Gurbuz, and M. Karavus. 2014. "Knowledge, attitudes and beliefs of Turkish women towards blood donation. Journal of Pakistan Medical Association 64(8): 869-873.

Edgren, G., T. N. Tran, H. Hjalgrim, K. Rostgaard, A. Shanwell, K. Titlestad, A. Wikman, et al. 2007. Improving health profile of blood donors as a consequence of transfusion safety efforts. Transfusion 47(11): 2017-2024. https://doi.org/10.1111/j.15372995.2007.01425.x

Gillespie, T. W. and C. D. Hillyer. 2002. Blood donors and factors impacting the blood donation decision. Transfusion Medicine Reviews 16(2): 115-130. https://doi. org/10.1053/tmrv.2002.31461 
Glynn, S. A., G. B. Schreiber, E. L. Murphy, D. Kessler, M. Higgins, D. J. Wright, S. Mathew, Y. Tu, M. King and J. W. Smith. 2006. Factors influencing the decision to donate: Racial and ethnic comparisons. Transfusion 46(6): 980-990. https://doi. org/10.1111/j.1537-2995.2006.00831.x

Guest, J. F., V. Munro and R. F. Cookson. 1998. The annual cost of blood transfusions in the United Kingdom. Transfusion Medicine 20(2): 111-118. https://doi.org/10.1046/ j.1365-2257.1998.00112.x

Healy, K. 2000. Embedded altruism: Blood collection regimes and the European union's donor population. American Journal of Sociology 105(6): 1633-1657. https://doi. org/10.1086/210468

Holdershaw, J., P. Gendall and M. Wright. 2003. Predicting willingness to donate blood. Australasian Marketing Journal 11(1): 87-96. https://doi.org/10.1016/S14413582(03)70120-7

Hollingsworth, B. and J. Wildman. 2004. What population factors influence the decision to donate. Transfusion Medicine 14(1): 9-12. https://doi.org/10.1111/j.09587578.2004.00473.x

Hupfer, M. E., D. W. Taylor and J. A. Letwin. 2005. Understanding Canadian student motivations and beliefs about giving blood. Transfusion 45(2): 149-61. https:// doi.org/10.1111/j.1537-2995.2004.03374.x

Jabatan Perdana Menteri. 2010. Government transformation programme. Report. Putrajaya: Prime Ministers Office. doi:10.1007/s13398-014-0173-7.2.

James, A. B., D. G. Demmons, G. B. Schreiber, C. D. Hillyer, and B. H. Shaz. 2011. Contribution of attitudinal factors to blood donation in African American church attendees. Transfusion 51(1): 158-165. https://doi.org/10.1111/j.15372995.2010.02775.x

Kamhieh-Milz, S., J. Kamhieh-Milz, Y. Tauchmann, T. Ostermann, Y. Shah, U. Kalus, A. Salama and A. Michalsen. 2016. Regular blood donation may help in the management of hypertension: An observational study on 292 blood donors. Transfusion 56(3): 637-644. https://doi.org/10.1111/trf.13428

Kasraian, L. 2010. Causes of discontinuity of blood donation among donors in Shiraz, Iran: Cross-sectional study. Sao Paulo Medical Journal 128(5): 272-275. https://doi. org/10.1590/S1516-31802010000500006

Leitman, S. F., J. N. Browning, Y. Y. Yau, G. Mason, H. G. Klein, C. Conry-Cantilena and C. D. Bolan. 2003. Hemochromatosis subjects as allogeneic blood donors: A prospective study. Transfusion 43(11): 1538-1544. https://doi.org/10.1046/ j.1537-2995.2003.00570.x

Lim, C. W. 2014. Top 10 things you didn't know about blood donation. The Star, 2 August. Maddala, G. S. 1986. Limited-dependent and qualitative variables in econometrics. Cambridge: Cambridge University Press.

Marantidou, O., L. Loukopoulou, E. Zervou, G. Martinis, A. Egglezou, P. Fountouli, P. Dimoxenous, M. Parara, M. Gavalaki, and A. Maniatis. 2007. Factors that motivate and hinder blood donation in Greece. Transfusion Medicine 17(6): 443450. https://doi.org/10.1111/j.1365-3148.2007.00797.x

McCullagh, P. 1980. Regression models for ordinal data (with discussion). Journal of the Royal Statistical Society 42 (Series B): 109-142. 
McKelvey, R. D. and W. Zavoina. 1975. A statistical model for the analysis of ordinal level dependent variables. The Journal of Mathematical Sociology 4(1): 103-120. https://doi.org/10.1080/0022250X.1975.9989847

Mesch, D. J., M. S. Brown, Z. I. Moore and A. D. Hayat. 2011. Gender differences in charitable giving. International Journal of Nonprofit and Voluntary Sector Marketing 16(4): 342-355. https://doi.org/10.1002/nvsm.432

Ministry of Health Malaysia. 2014. Annual report 2014. Putrajaya: Ministry of Health Malaysia. http://www.moh.gov.my/english.php/pages/view/56.

. 2011. Annual report 2011. Putrajaya: Ministry of Health Malaysia. http://www. moh.gov.my/english.php/pages/view/196.

2009. Annual report 2009. Putrajaya: Ministry of Health Malaysia. http://www. moh.gov.my/english.php/pages/view/196.

2007. Annual report 2007. Putrajaya: Ministry of Health Malaysia. http://www. moh.gov.my/english.php/pages/view/196.

2006. Malaysia's health 2006. Putrajaya: Ministry of Health Malaysia. http://moh. gov.my/images/gallery/publications/mh/Malaysia Health 2006-2.pdf.

Misje, A. H., V. Bosnes, O. Gåsdal and H. E. Heier. 2005. Motivation, recruitment and retention of voluntary non-remunerated blood donors: A survey-based questionnaire study. Vox Sanguinis 89(4): 236-244. https://doi.org/10.1111/ j.1423-0410.2005.00706.x

Ngim, C. F., N. M. Lai, H. Ibrahim and V. Ratnasingam. 2013. Attitudes towards prenatal diagnosis and abortion in a multi-ethnic country: A survey among parents of children with thalassaemia major in Malaysia. Journal of Community Genetics 4(2): 215-221. https://doi.org/10.1007/s12687-012-0133-x

Ou-Yang, J., C.-H. Bei, B. He and X. Rong. 2017. Factors influencing blood donation: A cross-sectional survey in Guangzhou, China. Transfusion Medicine. 27(4): 256267. https://doi.org/10.1111/tme.12410

Ou, Y., K. K. W. Yau, C. M. Poon, Y. V. Hui, S. S. Lee and C. K. Lee. 2015. Donation frequency and its association with demographic characteristics: A 1-year observational study. Transfusion Medicine 25 (6): 366-73. https://doi.org/10.1111/ tme. 12267

Penang Institute. 2014. Population by ethnicity and age, Penang 2014. In Data asas sosioekonomi negeri Pulau Pinang (Penang in numbers) 2014/2015, 1-158. Penang, Malaysia: Penang Institute.

Piliavin, J. A. and P. L. Callero. 1991. Giving blood: The development of an altruistic identity. The Johns Hopkins Series in Contemporary Medicine and Public Health. Baltimore: John Hopkins University Press.

Powers, D. A. and Y. Xie. 2008. Statistical methods for categorical data analysis. 2nd ed. Bingley: Emerald Group Publishing Limited.

Saberton, P. J., A. Paez, K. B. Newbold and N. M. Heddle. 2009. Geographical variations in the correlates of blood donor turnout rates: An investigation of Canadian metropolitan areas. International Journal of Health Geographics 8(1): 56. https:// doi.org/10.1186/1476-072X-8-56 
Shenga, N., K. R. Thankappan, C. C. Kartha and R. Pal. 2010. Analyzing sociodemographic factors amongst blood donors. Journal of Emergencies, Trauma, and Shock 3(1): 21-25. https://doi.org/10.4103/0974-2700.58667

Stewart, K. R., C. R. France, A. W. Rader and J. C. Stewart. 2006. Phlebotomist interpersonal skill predicts a reduction in reactions among volunteer blood donors. Transfusion 46(8): 1394-1401.

The Star. 2010. Thalassaemia at a glance. 6 June.

Veldhuizen, I. J. T, C. J. M. Doggen, F. Atsma and W. L. A. M. De Kort. 2009. Donor profiles: Demographic factors and their influence on the donor career. Vox Sanguinis 97(2): 129-138. https://doi.org/10.1111/j.1423-0410.2009.01201.x

Volken, T., C. Weidmann, T. Bart, Y. Fischer, H. Klüter and P. Rüesch. 2013. Individual characteristics associated with blood donation: A cross-national comparison of the German and Swiss population between 1994 and 2010. Transfusion Medicine and Hemotherapy 40(2): 133-138. https://doi.org/10.1159/000349985

Wiwanitkit, V. 2002. Knowledge about blood donation among a sample of Thai university students. Vox Sanguinis 83(2): 97-99. https://doi.org/10.1046/j.14230410.2002.00209.x

Wooi Seong, K. 2017. Overcoming blood supply challenges in multi-ethnic donor and patient populations: The Malaysia experience. International Society of Blood Transfusion 12(1): 4-10. https://doi.org/10.1111/voxs.12329

Wooi Seong, K., V. Raffeal and Y. Ayob. 2014. Adopting a proactive approach to blood shortages: Experience from the national blood centre, Malaysia. ISBT Science Series 9(1): 189-192. https://doi.org/10.1111/voxs.12104

World Health Organization. 2016. Blood safety and availability: Factsheet. Geneva: World Health Organization. http://www.who.int/mediacentre/factsheets/fs279/en/. 2012. Blood donor selection: Guidelines on assessing donor suitability for blood donation. Geneva: World Health Organization. http://apps.who.int/iris/ handle/10665/76724.

. 2010. Towards 100\% voluntary blood donation: A global framework for action. Geneva: World Health Organization. http://www.who.int/bloodsafety/ publications/9789241599696/en/. 